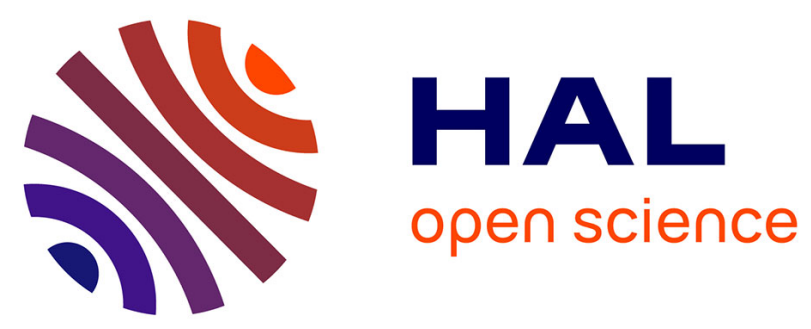

\title{
SiRNA LNCs - A novel platform of lipid nanocapsules for systemic siRNA administration
}

\author{
Stephanie David, Pauline Resnier, A. Guillot, Bruno Pitard, Jean-Pierre \\ Benoit, Catherine Passirani-Malleret
}

\section{- To cite this version:}

Stephanie David, Pauline Resnier, A. Guillot, Bruno Pitard, Jean-Pierre Benoit, et al.. SiRNA LNCs - A novel platform of lipid nanocapsules for systemic siRNA administration. European Journal of Pharmaceutics and Biopharmaceutics, 2012, 81 (2), pp.448-42. 10.1016/j.ejpb.2012.02.010 . hal03165467

\section{HAL Id: hal-03165467 \\ https://univ-angers.hal.science/hal-03165467}

Submitted on 10 Mar 2021

HAL is a multi-disciplinary open access archive for the deposit and dissemination of scientific research documents, whether they are published or not. The documents may come from teaching and research institutions in France or abroad, or from public or private research centers.
L'archive ouverte pluridisciplinaire HAL, est destinée au dépôt et à la diffusion de documents scientifiques de niveau recherche, publiés ou non, émanant des établissements d'enseignement et de recherche français ou étrangers, des laboratoires publics ou privés. 
Note

\title{
siRNA LNCs - A novel platform of lipid nanocapsules for systemic siRNA administration
}

\author{
Stephanie David ${ }^{\text {a,b,c }}$, Pauline Resnier ${ }^{\text {a,b }}$, Alexis Guillot ${ }^{\mathrm{a}, \mathrm{b}}$, Bruno Pitard ${ }^{\mathrm{c}}$, Jean-Pierre Benoit ${ }^{\mathrm{a}, \mathrm{b}}$, \\ Catherine Passirani ${ }^{\mathrm{a}, \mathrm{b}, *}$ \\ a LUNAM Université, Université d'Angers, Angers, France \\ b INSERM U1066 MINT, Micro et Nanomedecines biomimétiques, Angers, France \\ ${ }^{\mathrm{c}}$ INSERM, UMR915, Université de Nantes, Nantes, France
}

\section{A R T I C L E I N F O}

\section{Article history:}

Received 24 November 2011

Accepted in revised form 13 February 2012

Available online 21 February 2012

\section{Keywords:}

Nanocarrier

Lipoplexes

Formulation

siRNA quantification

Cationic lipids

Systemic administration

\begin{abstract}
A B S T R A C T
Several siRNA (small interfering RNA) therapeutics are undergoing clinical trials for cancer, respiratory diseases or macular degeneration, but most are administrated locally. In order to overcome the different barriers to attain an efficient siRNA action after systemic administration, nanocarriers able to carry and protect siRNA are awaited. With this aim, we developed a new platform of siRNA lipid nanocapsules (LNCs) using different cationic lipids, combining the properties of LNCs (siRNA protection and targeting) and lipoplexes (efficient siRNA delivery into the cell). The formulation was revealed to contain different compartments. A siRNA quantification method based on UV spectroscopy was developed to locate and quantify siRNA in each compartment. All in all, these novel siRNA LNCs presented sizes of about $55 \mathrm{~nm}$ with a neutral surface charge and siRNA encapsulation efficiencies up to 65\% representing appropriate characteristics for systemic administration.
\end{abstract}

(c) 2012 Elsevier B.V. All rights reserved.

\section{Introduction}

siRNA is rapidly broken down by nucleases and other blood components after intravenous administration. Moreover, between the administration and action site, different barriers have to be overcome. Therefore, different siRNA modifications and siRNA vectors have already been described in the literature, with a view to finding the "ideal" vector [1].

Lipid nanocapsules (LNCs), consisting of a lipid liquid core of triglycerides and a rigid shell of lecithin and polyethylene glycol, were developed in our laboratory [2]. The simple formulation process is based on phase inversions of an emulsion. These LNCs were recently modified to encapsulate DNA, complexed with cationic lipids, forming lipoplexes. These DNA LNCs were efficient for in vitro and in vivo transfection [3-5] in contrast to lipoplexes that were only efficient in vitro.

The association between LNCs and lipoplexes should combine LNC properties (nucleic acid protection, prolonged circulation time, possibility of active or passive targeting) with lipoplex properties (internalisation in cells, permitting nucleic acid action). With this in mind, the objective of this work was to develop siRNA LNCs allowing efficient systemic siRNA administration. In this study,

\footnotetext{
* Corresponding author. Inserm U646, Université d'Angers, IBS-CHU, 4 rue Larrey, 49933 Angers Cedex 9, France. Tel.: +33 244 688534; fax: +33 244688546.

E-mail address: catherine.passirani@univ-angers.fr (C. Passirani).
}

various ratios of different cationic lipids were used to formulate siRNA LNCs, and the size, charge and payload characteristics of these novel promising nanocarriers were assessed.

\section{Materials and methods}

\section{1. siRNA LNC formulation}

Basic lipid nanocapsules (LNCs) were formulated, as described before [2], by mixing 20\% w/w Labrafac WL 1349 (caprylic-capric acid triglycerides, Gatefossé SA, Saint-Priest, France), 1.5\% w/w Lipoid S75-3 (Lipoid GmbH, Ludwigshafen, Germany), 17\% w/w Solutol HS 15 (BASF, Ludwigshafen, Germany), 1.8\% w/w NaCl (Prolabo, Fontenay-sous-Bois, France) and $59.8 \% \mathrm{w} / \mathrm{w}$ water (obtained from a Milli-Q system, Millipore, Paris, France) together under magnetic stirring. Three temperature cycles between 60 and $95{ }^{\circ} \mathrm{C}$ were performed to obtain phase inversions of the emulsion obtained after mixing all the components. Then, a rapid cooling and dilution with ice-cooled water (1:1.4) at the phase inversion temperature (PIT) led to LNC formation.

To obtain siRNA LNCs, the water in the last step was replaced by lipoplexes which were prepared by adding equal volumes of siRNA (here a model siRNA targeted against PCSK9, (sense sequence: GGAAGAUCAUAAUGGACAGdTdT) Eurogenetec, Seraing, Belgium) and liposomes in a defined charge ratio of cationic lipid charge 
versus anionic siRNA charge. $\mathrm{NaCl}$ was added during preparation to obtain a final concentration of $0.15 \mathrm{M}$.

For liposome preparation, a cationic lipid DOSP (dioleylaminesuccinyl paromomycin) (synthesis previously described in [6]), bis(guanidinium)-tris(2-aminoethyl)amine-cholesterol (BGTC) (synthesis previously described in [7]) or DOTAP (1.2-dioleyl-3trimethylammoniumpropane) (Avanti ${ }^{\circledR}$ Polar Lipids Inc., Alabaster, AL, USA), solubilised in chloroform, was weighted in the ratio $1 / 1$ $(\mathrm{M} / \mathrm{M}), 3 / 2(\mathrm{M} / \mathrm{M})$ or $1 / 1(\mathrm{M} / \mathrm{M})$, respectively, with the neutral lipid 1.2-dioleyl-sn-glycero-3-phosphoethanolamine (DOPE) (Avanti ${ }^{\circledR}$ Polar Lipids Inc., Alabaster, AL, USA) to obtain a final concentration of $20 \mathrm{mM}$ of cationic lipid charge, considering the number of lipid charges per molecule ( 4 for DOSP, 2 for BGTC and 1 for DOTAP). After chloroform evaporation under vacuum, deionised water was added to hydrate the lipid film overnight at $4{ }^{\circ} \mathrm{C}$ which was sonicated the next day.

DOSP micelles were prepared in the same way without the addition of DOPE.

\section{Characterisation}

\subsection{Size and zeta potential measurements}

Size and zeta potential of siRNA LNCs were measured using a Malvern Zetasizer ${ }^{\circledR}$ (Nano Series ZS, Malvern Instruments SA, Worcestershire, UK) at $25^{\circ} \mathrm{C}$, in triplicate, after dilution in a ratio of $1: 100$ with deionised water.

\subsection{Agarose gel electrophoresis}

To verify siRNA encapsulation in LNC, Triton ${ }^{\circledR}$ X100 (Sigma, Saint-Quentin Fallavier, France) was added to destroy LNCs. Samples were mixed with OrangeBlue loading dye (Promega, Madison, WI, USA) before deposition on $1 \%$ agarose gel containing ethidium bromide (Sigma, Saint-Quentin Fallavier, France) and migration at $100 \mathrm{~V}$ for $30 \mathrm{~min}$.

\section{3. siRNA LNC purification}

Five hundred microlitre of siRNA LNC formulation was deposited on a $1.5 \times 40 \mathrm{~cm}$ Sepharose CL-4B column and were eluted with HEPES buffer ( $\mathrm{pH} 7.4$ ). Fractions of $500 \mu \mathrm{l}$ or $1 \mathrm{ml}$ were collected in glass tubes for further analysis; $100 \mu \mathrm{l}$ of each fraction was used for turbidity measurements and analysed at $580 \mathrm{~nm}$. PEG (polyethylene glycol) was quantified using $20 \mu \mathrm{l}$ of each fraction, which was mixed with $5 \mu \mathrm{K} \mathrm{KI} / \mathrm{I}_{2}$ and $180 \mu \mathrm{H}_{2} \mathrm{O}$ milli-Q before analysing at $492 \mathrm{~nm}$ using a Multiskan Ascent microplate reader (Thermo Fisher Scientific Cergy-Pontoise, France). Size and zeta potential measurements were taken as described above, and siRNA was evidenced using gel electrophoresis experiments.

\section{4. siRNA quantification}

One volume of the formulation was mixed with three volumes water (obtained from a Milli-Q-plus ${ }^{\circledR}$ system, Millipore, Paris, France), six volumes $1 \mathrm{M} \mathrm{NaOH}$ and two volumes chloroform, vortexed and immediately centrifuged for $15 \mathrm{~min}$ at $20,000 \mathrm{~g}$ and $4{ }^{\circ} \mathrm{C}$. The aqueous phase, containing free siRNA and siRNA liberated from lipoplexes outside LNCs, was removed and analysed with a UV spectrophotometer (UVIKON 922, Kontron Instruments, Munich, Germany) at $260 \mathrm{~nm}$. The volume removed for free siRNA quantification was replaced by ethanol. Then two volumes water and 10 volumes $\mathrm{NaOH} 1 \mathrm{M}$ were added before vortexing and centrifuged a second time for $15 \mathrm{~min}$ at $20,000 \mathrm{~g}$ and $4{ }^{\circ} \mathrm{C}$. The aqueous phase, containing the liberated siRNA from lipoplexes inside siRNA LNCs, was removed and analysed as previously mentioned at $260 \mathrm{~nm}$. To analyse free and encapsulated siRNA quantity in siRNA LNCs, the same procedure was used using two volumes of formulation and replacing water by $1 \mathrm{M} \mathrm{NaOH}$. The first aqueous phase contained free siRNA; the second aqueous phase contained siRNA encapsulated in siRNA LNCs. The siRNA quantity was calculated using a calibrating curve with different siRNA concentrations and compared to the total siRNA amount encapsulated in theory in siRNA LNCs. All samples were prepared in duplicate.

Table 1

Characteristics of siRNA lipoplexes used for siRNA LNC formulations.

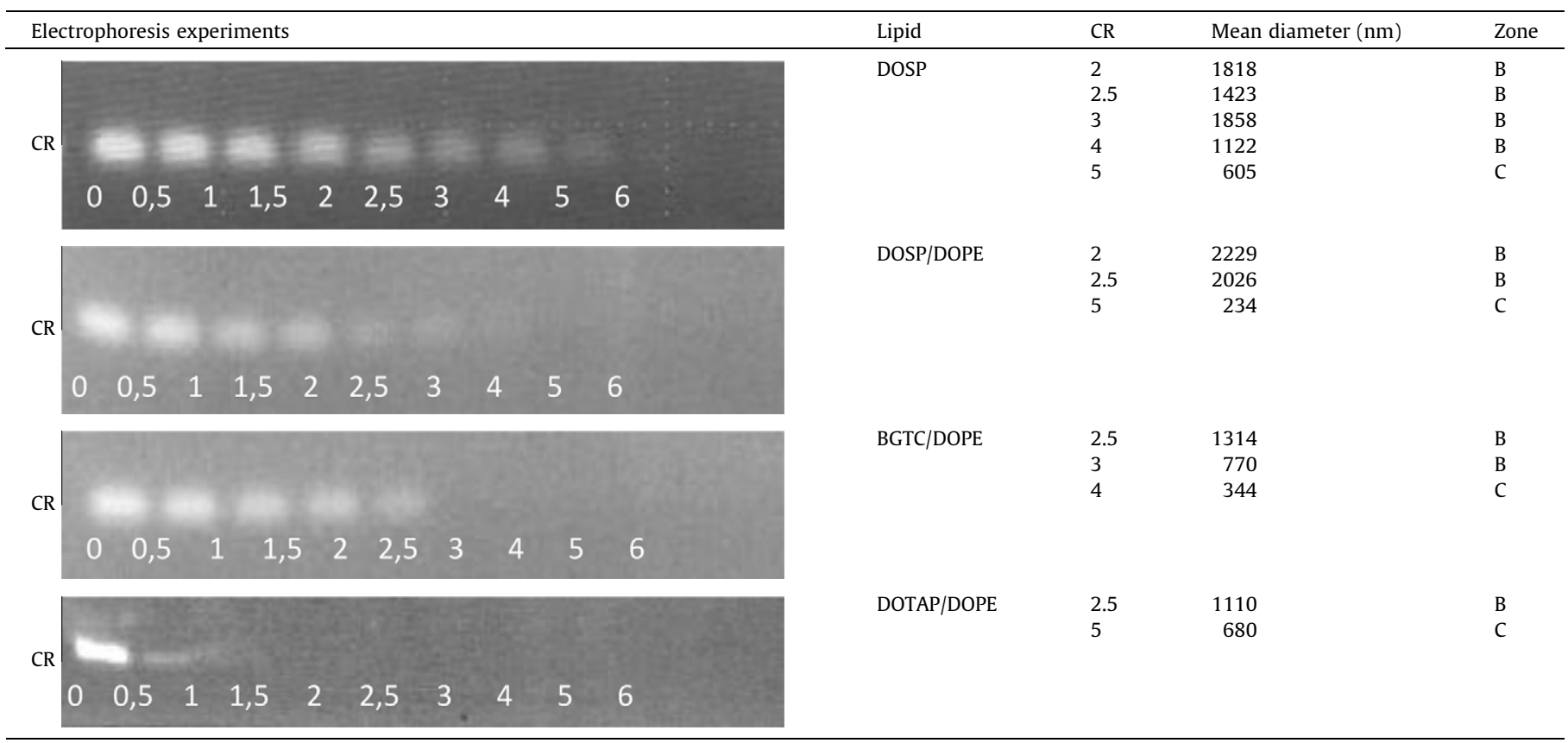




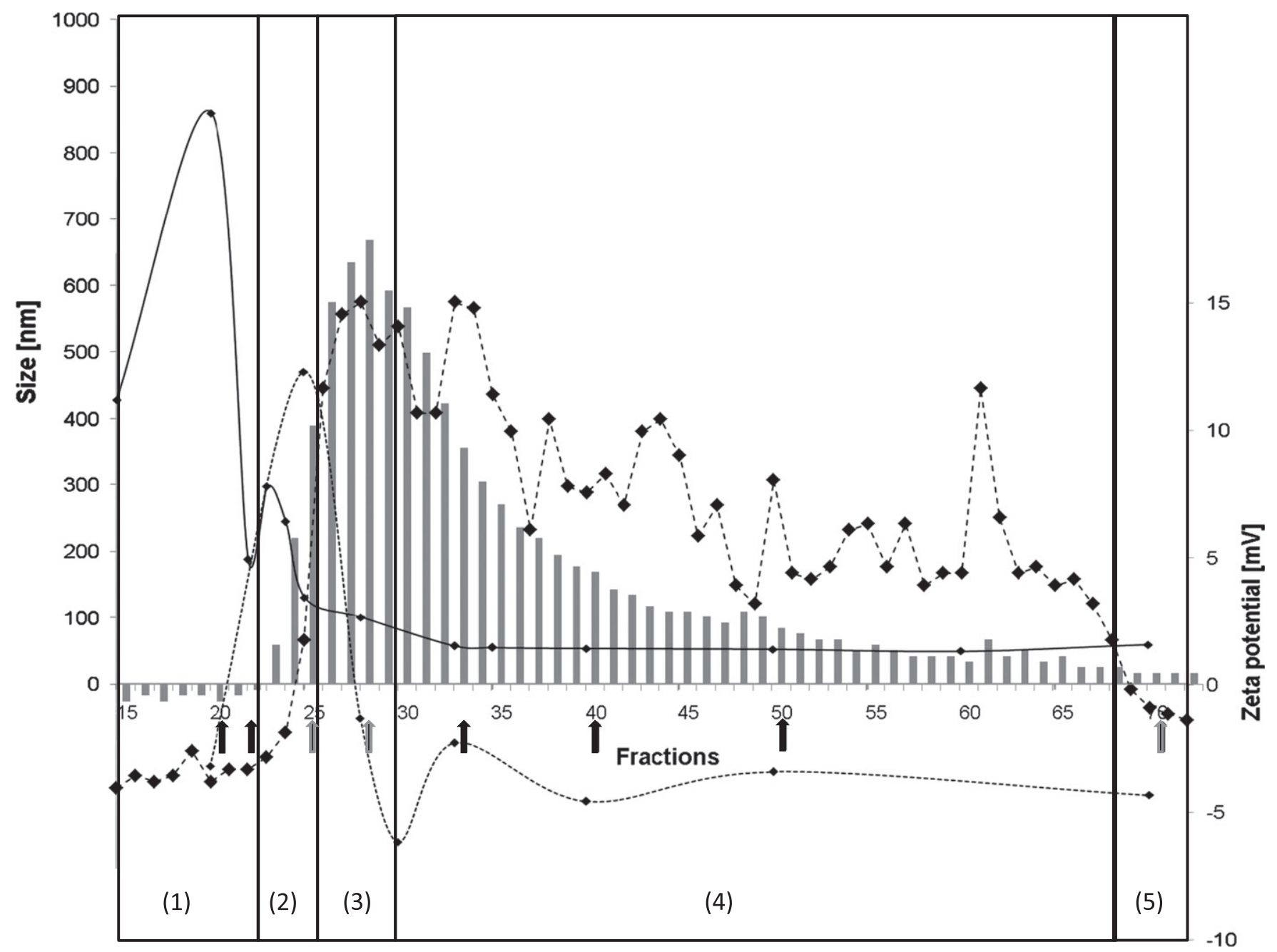

\begin{tabular}{|lc|c|c|c|c|c|}
\hline & & (1) lipo & (2) Ipx & (3) siLNC & (4) LNC/PEG & (5) siRNA \\
\hline Size & & $850 \mathrm{~nm}$ & $200-300 \mathrm{~nm}$ & $100 \mathrm{~nm}$ & $50 \mathrm{~nm}$ & $50 \mathrm{~nm}$ \\
\hline Zeta potential & - & - & $5-10 \mathrm{mV}$ & $-5-5 \mathrm{mV}$ & $-5 \mathrm{mV}$ & $-5 \mathrm{mV}$ \\
\hline Turbidity & - & - & + & + & + & - \\
\hline PEG & - & - & + & + & - \\
\hline siRNA & - & + & + & - & + \\
\hline Conclusion & empty liposomes & Lipoplexes & siRNA LNCs & $\begin{array}{c}\text { empty LNCs/ } \\
\text { free PEG }\end{array}$ & free siRNA \\
\hline
\end{tabular}

Fig. 1. Purification of DOTAP/DOPE/siRNA LNC formulation (CR 2.5) on Sepharose columns.

\section{Results and discussion}

\subsection{Lipoplex characterisation}

The colloidal stability of lipoplexes was determined at different charge ratios $(\mathrm{CR}=$ cationic lipid charge/siRNA charge $(+/-))$ for various cationic lipids (DOSP, DOSP/DOPE, BGTC/DOPE and DO$\mathrm{TAP} / \mathrm{DOPE}$ ) using size, fluorescence and electrophoresis analysis (Table 1). In the way as for DNA lipoplexes, three different zones of colloidal stability A, B and C could be determined with specific properties in each zone [8]. In summary, in zone A, the quantity of cationic lipid is not sufficient to complex all nucleic acids, so they are still detectable. In this zone, lipoplexes possess a small size and a negative surface charge. In zone B, all nucleic acids are complexed and are no longer detectable. The surface charge is neutral, which leads to aggregation and an augmented size. This was the case for all lipoplexes tested at CR 2 and 2.5, for DOSP/siRNA lipoplexes at CR 3 and 4 and for BGTC/DOPE/siRNA lipoplexes at CR 3. They presented a size over the arbitrary value of $700 \mathrm{~nm}$ and only a slight fluorescence in electrophoresis experiments. In zone C, the quantity of cationic lipids is predominant, and thus, the surface charge is positive leading to repulsion and smaller lipoplexes, which was observed for all lipoplexes tested at the CR 5 and for BGTC/ DOPE/siRNA lipoplexes at CR 4. To encapsulate lipoplexes in the 


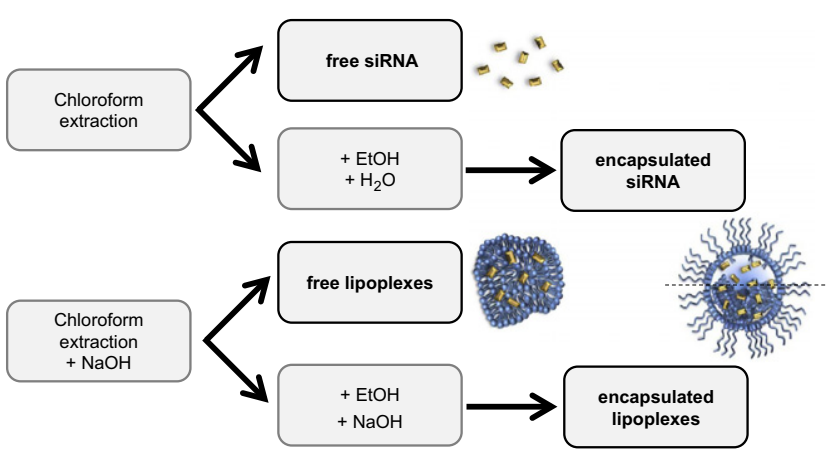

Fig. 2. Schematic representation of siRNA quantification. (For interpretation of the references to colour in this figure legend, the reader is referred to the web version of this article.)

liquid lipid core of LNCs, lipoplexes of zone B and C were chosen as, in zone $B$, the neutral surface charge, and the aggregation of lipoplexes suggests rather a lipophilic affinity; moreover, DNA lipoplexes of zone $\mathrm{C}$ were already encapsulated efficiently in LNCs.

\section{SiRNA LNC formulation and characterisation}

Basic LNCs were developed by Heurtault et al. [2]. Their easy formulation process and their good characterisation make these nanocarriers attractive. To formulate them, the components were mixed together, and temperature cycles around the phase inversion temperature (PIT) were performed. In the last step, a large quantity of water was added at the PIT of the last cycle, resulting in the rapid cooling and dilution of the emulsion and the formation of LNCs. The addition of lipoplexes in the cooling water at the end of the formulation process contributed to siRNA LNC formulation and had the advantage of avoiding their exposure to high temperatures during the formulation.

siRNA encapsulation in LNCs was checked using electrophoresis experiments. As sometimes a low fluorescence band was visible, indicating an incomplete complexation or encapsulation, purification of siRNA LNCs DOTAP/DOPE CR 2.5 was performed on Sepharose columns. This also made it possible to determine whether siRNA was encapsulated in LNCs or simply complexed in lipoplexes. The collected fractions were then analysed by performing size and zeta potential measurements, PEG quantification, turbidity measurements and gel electrophoresis. The final result of these analyses (Fig. 1) suggested the presence of five different compartments in the formulation: (1) empty liposomes, (2) lipoplexes, (3) siRNA LNCs, (4) empty LNCs and (5) free siRNA. In the first com- partment, empty liposomes were suspected as no PEG and no siRNAs were found and a size of about $850 \mathrm{~nm}$ was measured. In the second compartment, the size diminished, siRNAs were detected, the turbidity augmented and a slightly positive zeta potential was measured, indicating the presence of DOTAP/DOPE lipoplexes (CR 2.5). In the third compartment, PEG and siRNA were detected with a size of about $100 \mathrm{~nm}$, and a near neutral zeta potential was measured, suggesting the presence of siRNA LNCs. In the fourth compartment, PEG but no siRNA was detected, and sizes about $50 \mathrm{~nm}$ and a slightly negative zeta potential were measured, indicating empty LNCs and/or free PEG. In the last compartment, no PEG was detected, but siRNAs were found, indicating free siRNA.

According to these results, our hypothesis is that siRNA can be situated in 4 different compartments: in the second compartment in lipoplexes outside LNCs; in the third compartment either (3a) complexed with cationic lipids in LNCs or (3b) associated with other components of the LNC formulation but dissociated from cationic lipids; or in the fifth compartment as free siRNA. To quantify and locate siRNA in the formulation, a quantification method using UV spectrometry analysis at $260 \mathrm{~nm}$ was developed (Fig. 2). Free siRNA was quantified using a simple chloroform extraction to separate other constituents of the formulation which interfered during UV spectroscopy analysis. siRNAs in lipoplexes outside LNCs were quantified in the same way, but $\mathrm{NaOH}$ was added to dissociate lipoplexes. siRNAs in LNCs were quantified using the "separated" formulations (without free siRNA and/or without lipoplexes) by addition of ethanol, to dissociate LNCs, and $\mathrm{NaOH}$, to dissociate siRNAs from cationic lipids. To determine the siRNA quantity, calibrating curves for the different treatments were performed using siRNA quantities between 0 and the maximal theoretical charge in one volume siRNA LNC formulation $(c=0.25 \mathrm{~g} / \mathrm{l})$.

Afterwards, siRNA LNCs were formulated with different cationic lipids, and their size, zeta potential and encapsulation efficiency were determined (Table 2). The basic LNC formulation presented a size of $55 \mathrm{~nm}$ with limited distribution indicated by a very low polydispersity index (PDI) of 0.04 and a slightly negative zeta potential of about $-5 \mathrm{mV}$. The zeta potential of formulations prepared by the novel process was comprised between -25 and $+25 \mathrm{mV}$, and the encapsulation efficiencies in LNCs were situated between $4 \%$ and $65 \%$. Both varied in relation to the cationic lipids used for lipoplex formation and the CR. The sizes were around $55 \mathrm{~nm}$ with a very low PDI with the exception of siRNA LNCs using DOTAP/DOPE/siRNA lipoplexes. Indeed, at CR 2.5, they showed two distinct populations of about 55 and $185 \mathrm{~nm}$, and at CR 5, a size of $125 \mathrm{~nm}$ with the highest siRNA encapsulation efficiency at 65\%. These lipids and CR were also previously used for DNA encapsula-

Table 2

Size, zeta potential measurements and encapsulation efficiency of siRNA LNC formulations.

\begin{tabular}{|c|c|c|c|c|c|c|c|c|c|c|}
\hline \multirow{2}{*}{\multicolumn{2}{|c|}{$\begin{array}{l}\text { LNC formulation } \\
\text { Basic LNC formulation } \\
\text { LNC siRNA }\end{array}$}} & \multirow{3}{*}{$\begin{array}{l}\text { Size }(\mathrm{nm}) \\
55.5 \pm 0.5\end{array}$} & \multirow{3}{*}{$\begin{array}{l}\text { PDI } \\
0.04 \pm 0.01\end{array}$} & \multirow{3}{*}{$\begin{array}{l}\text { Zeta potential }(\mathrm{mV}) \\
-5.2 \pm 0.5\end{array}$} & \multicolumn{5}{|c|}{ Encapsulation efficiency (\%) } & \multirow[t]{3}{*}{ Total siRNA found (\%) } \\
\hline & & & & & \multicolumn{4}{|c|}{ Compartment 1} & \multirow[t]{2}{*}{$\operatorname{siLNC}(3 a+3 b)$} & \\
\hline Cationic lipids & $\mathrm{CR}[ \pm]$ & & & & (5) siRNA & (2) Lpx & $\left(3 \mathrm{a}^{2}\right)$ siLNC & $\left(3 b^{3}\right)$ siLNC & & \\
\hline BGTC/DOPE & 2.5 & $55.3 \pm 0.1$ & $0.13 \pm 0.03$ & $1.5 \pm 0.7$ & $20 \pm 0$ & $66 \pm 3$ & $3 \pm 1$ & $10 \pm 4$ & $13 \pm 3$ & $108 \pm 4$ \\
\hline DOSP & $\begin{array}{l}2 \\
2.5 \\
5\end{array}$ & $\begin{array}{l}51.6 \pm 0.2 \\
60.4 \pm 1.0 \\
52.8 \pm 0.0\end{array}$ & $\begin{array}{l}0.07 \pm 0,00 \\
0.10 \pm 0.02 \\
0.08 \pm 0.00\end{array}$ & $\begin{array}{r}-2.4 \pm 0.7 \\
-1.1 \pm 0.1 \\
24.1 \pm 1.7 \\
10.1 \pm 3.2 \\
-3.7 \pm 4.3\end{array}$ & $\begin{array}{c}2 \pm 1 \\
8 \pm 9 \\
20 \pm 12\end{array}$ & $\begin{array}{l}94 \pm 5 \\
75 \pm 18 \\
65 \pm 13\end{array}$ & $\begin{array}{c}0 \\
13 \pm 9 \\
11 \pm 1\end{array}$ & $\begin{array}{l}4 \pm 6 \\
4 \pm 1 \\
3 \pm 0\end{array}$ & $\begin{aligned} & 4 \pm 6 \\
17 & \pm 10 \\
14 & \pm 1\end{aligned}$ & $\begin{array}{l}107 \pm 7 \\
117 \pm 14 \\
126 \pm 8\end{array}$ \\
\hline DOSP/DOPE & $\begin{array}{l}2 \\
2.5 \\
5\end{array}$ & $\begin{array}{l}53.3 \pm 0.2 \\
59.7 \pm 0.5 \\
61.4 \pm 0.3\end{array}$ & $\begin{array}{l}0,03 \pm 0.01 \\
0.09 \pm 0.01 \\
0.15 \pm 0.03\end{array}$ & $\begin{array}{r}-25.7 \pm 1.9 \\
-1.5 \pm 0.4 \\
7.8 \pm 0.9\end{array}$ & $\begin{array}{r}4 \pm 1 \\
2 \pm 2 \\
12 \pm 4\end{array}$ & $\begin{array}{l}80 \pm 8 \\
91 \pm 0 \\
73 \pm 1\end{array}$ & $\begin{array}{c}8 \pm 12 \\
2 \pm 2 \\
11 \pm 4\end{array}$ & $\begin{array}{l}7 \pm 2 \\
5 \pm 0 \\
3 \pm 0\end{array}$ & $\begin{array}{c}15 \pm 10 \\
7 \pm 2 \\
15 \pm 5\end{array}$ & $\begin{array}{r}75 \pm 9 \\
88 \pm 2 \\
105 \pm 6\end{array}$ \\
\hline DOTAP/DOPE & 2.5 & $\begin{array}{c}53.5 \pm 6.8 \\
184.1 \pm 28.4\end{array}$ & $0.29 \pm 0.03$ & $-0.3 \pm 0.5$ & 0 & $73 \pm 19$ & $11 \pm 16$ & $16 \pm 3$ & $27 \pm 19$ & $100 \pm 5$ \\
\hline & 5 & $124.8 \pm 0.6$ & $0.24 \pm 0.00$ & $1.6 \pm 0.3$ & 0 & $34 \pm 1$ & $20 \pm 4$ & $45 \pm 5$ & $65 \pm 2$ & $79 \pm 7$ \\
\hline
\end{tabular}


tion in DNA LNCs forming efficient nanocarriers for in vitro [3] and in vivo [4] transfection. The size of DOTAP/DOPE siRNA LNCs (CR 5) was similar to that of other promising siRNA vectors (100$170 \mathrm{~nm}$ ), with efficient transfection in vivo after systemic administration [9]. However, the first siRNA nanocarriers for systemic administration that are in phase I clinical trials (CALAA-01 [10]) have sizes of about $70 \mathrm{~nm}$. This corresponds to siRNA LNC formulations containing the other lipids, but in contrast, they present only half or lower encapsulation efficiencies.

In summary, we developed a new platform of siRNA LNCs showing appropriate characteristics for systemic administration with good encapsulation efficiencies and/or small sizes and neutral surface charges. However, further investigations need now to be carried out to test their transfection efficiency in vitro and in vivo and to find a compromise between a small size and a high siRNA payload.

\section{References}

[1] S. David, B. Pitard, J.P. Benoit, C. Passirani, Non-viral nanosystems for systemic siRNA delivery, Pharmacol. Res. 62 (2010) 100-114.

[2] B. Heurtault, P. Saulnier, B. Pech, J.E. Proust, J.P. Benoit, A novel phase inversion-based process for the preparation of lipid nanocarriers, Pharm. Res. 19 (2002) 875-880.
[3] M. Morille, C. Passirani, E. Letrou-Bonneval, J.P. Benoit, B. Pitard, Galactosylated DNA lipid nanocapsules for efficient hepatocyte targeting, Int. J. Pharm. 379 (2009) 293-300.

[4] M. Morille, C. Passirani, S. Dufort, G. Bastiat, B. Pitard, J.L. Coll, J.P. Benoit, Tumor transfection after systemic injection of DNA lipid nanocapsules, Biomaterials (2010).

[5] A. Vonarbourg, C. Passirani, L. Desigaux, E. Allard, P. Saulnier, O. Lambert, J.P. Benoit, B. Pitard, The encapsulation of DNA molecules within biomimetic lipid nanocapsules, Biomaterials 30 (2009) 3197-3204.

[6] L. Desigaux, M. Sainlos, O. Lambert, R. Chevre, E. Letrou-Bonneval, J.P. Vigneron, P. Lehn, J.M. Lehn, B. Pitard, Self-assembled lamellar complexes of siRNA with lipidic aminoglycoside derivatives promote efficient siRNA delivery and interference, Proc. Natl. Acad. Sci. USA 104 (2007) 16534-16539.

[7] J.P. Vigneron, N. Oudrhiri, M. Fauquet, L. Vergely, J.C. Bradley, M. Basseville, P. Lehn, J.M. Lehn, Guanidinium-cholesterol cationic lipids: efficient vectors for the transfection of eukaryotic cells, Proc. Natl. Acad. Sci. USA 93 (1996) 96829686.

[8] B. Pitard, Supramolecular assemblies of DNA delivery systems, Somat. Cell Mol. Genet. 27 (2002) 5-15.

[9] K.P. Mahon, K.T. Love, K.A. Whitehead, J. Qin, A. Akinc, E. Leshchiner, I. Leshchiner, R. Langer, D.G. Anderson, Combinatorial approach to determine functional group effects on lipidoid-mediated siRNA delivery, Bioconjug. Chem. 21 (2010) 1448-1454.

[10] M.E. Davis, J.E. Zuckerman, C.H.J. Choi, D. Seligson, A. Tolcher, C.A. Alabi, Y. Yen, J.D. Heidel, A. Ribas, Evidence of RNAi in humans from systemically administered siRNA via targeted nanoparticles, Nature 464 (2010) 1067-1070. 